\title{
Patterns and predictors of academic dishonesty in Romanian university students
}

\author{
Bob Ives ${ }^{1}$ - Madalina Alama ${ }^{1}$ - Liviu Cosmin Mosora ${ }^{2}$. \\ Mihaela Mosora $^{2}$ - Lucia Grosu-Radulescu ${ }^{2}$. \\ Aurel Ion Clinciu ${ }^{3}$ - Ana-Maria Cazan ${ }^{3}$ - Gabriel Badescu ${ }^{4}$. \\ Claudiu Tufis $^{5} \cdot$ Mihaela Diaconu $^{6} \cdot$ Amalia Dutu $^{6}$
}

(C) Springer Science+Business Media Dordrecht 2016

\begin{abstract}
Academic dishonesty in higher education is an increasingly visible problem throughout the world and in Romania in particular. A total of 1127 university students from six public Romanian universities were surveyed for their experiences and beliefs with 22 behaviors that might be considered academically dishonest. A five-factor solution to the
\end{abstract}

Bob Ives

rives@unr.edu

Madalina Alama

malama@nevada.unr.edu

Liviu Cosmin Mosora

mosoracosmin@yahoo.com

Mihaela Mosora

mihaela.mosora@gmail.com

Lucia Grosu-Radulescu

lucia.grosu@rei.ase.ro

Aurel Ion Clinciu

a_clinciu@yahoo.com

Ana-Maria Cazan

ana_maria_cazan@yahoo.com

Gabriel Badescu

badescu@fspac.ro

Claudiu Tufis

ctufis@gmail.com 
frequencies of these behaviors was interpretable and accounted for more than half of the total variance. How acceptable students believed the behaviors were and how often students witnessed other students engage in these behaviors were consistent predictors of the frequency of the behaviors, with small to medium effect sizes. Demographic predictors of these behaviors, including gender, academic specialty, year in school, institution, grade average, and scholarship status, predicted very little variance in the behaviors. Implications and limitations of the study, as well as limitations of research in the field, are discussed.

Keywords Academic integrity $\cdot$ Academic dishonesty $\cdot$ Romania $\cdot$ University

In December of 2014, the Prime Minister of Romania sent a letter to the University of Bucharest relinquishing the doctoral degree that he obtained there amid accusations that he plagiarized a significant portion of his dissertation (Marinas 2014). A few weeks later, the Prime Minister issued a decree permitting people to relinquish their doctoral degrees without any explanation or investigation. Over 1300 people, mostly scientists in Romania, sign a letter of protest for this action (Abbott 2015). The case first gained attention in an article in Nature in June of 2012, which disclosed the suspected plagiarism (The Associated Press 2012). Romania's National Ethics Council cleared the Prime Minister of these plagiarism charges, but the ethics committee of the University of Bucharest reaffirmed the charges (Schiermeier 2012a). Romania's National Council for the Attestation of University Titles concluded unanimously that Ponta was guilty of plagiarizing about 85 pages of his dissertation, but the council was promptly dissolved by the acting Minister of Education before issuing a report (Bailey 2012; Schiermeier 2012b).

While this case gained international visibility when the Prime Minister was running for President of Romania in 2014, other recent evidence of concerns about academic integrity in Romanian institutions of higher education is not difficult to find. A Romanian Minister of Education was forced to resign recently amid accusations of plagiarism of a book, while another nominee for Minister of Education withdrew her nomination after accusations of plagiarism (Bailey 2012; The Associated Press 2012). A rector, a former rector, and a vice rector of the Medical and Pharmacy University of Târgu Mureș were all accused of plagiarism of academic papers. The Romanian National Ethics Council was dissolved on the day that their

Mihaela Diaconu

diaconu_m2005@yahoo.com

Amalia Dutu

pandelica.amalia@yahoo.com

1 University of Nevada, Reno, USA

2 Academia de Studii Economice, Bucharest, Romania

3 Universitatea Transilvania, Brasov, Romania

4 Universitatea Babes-Bolyai, Cluj, Romania

5 Universitatea din Bucuresti, Bucharest, Romania

6 Universitatea din Pitesti, Pitesti, Romania 
report on these cases was presented to the Ministry of Science. The report has not been released, but members of the council have indicated that there was clear evidence of plagiarism in all three cases (Abbott 2012; Hantz 2012). A Pro-Dean at the Academy for Economic Studies in Bucharest was accused of accepting bribes for grades on examinations, leading to a search of his home and office (Romania Insider 2014). A rector of Ovidius University was arrested in 2013 for accepting bribes for examinations and admissions (Newsromania 2013). The University of Bucharest recently asked the National Ethics Council to verify the dissertation of the mayor of the city of Craiova (Popescu 2014). In 2013, for the first time, a Romanian publisher was found guilty of plagiarism in a court of law (Stroe 2013).

Romanian scholars and news media have argued that a culture of academic dishonesty is embedded in Romanian higher education (Cole 2013; Galloway 2013; Stan and Turcescu 2004). In Romanian universities, "corruption can become a way of life" (Comsa et al. 2007, p. 73). Although Romanian universities with greater academic integrity ratings publish more than those with lower integrity ratings, Romanian universities lack the tools and the will to fight plagiarism among faculty (Mungiu-Pippidi 2011). Similarly, students who commit plagiarism in Romania typically face less severe consequences than those in Western European countries (Comsa et al. 2007). For decades, Romanian scholars published their work in journals sponsored by their own universities and departments. These journals often had little meaningful peer review (Baciu et al. 2010). Romanian universities have lacked promotion criteria based on scholarly productivity (Zaharia 2009). Instead, internal criteria to evaluate scholarly activity have been designed to "protect the existing faculty members" (Baciu et al. 2010, p. 71).

Certainly, problems with academic integrity are not unique to Romania. An independent investigation of the University of North Carolina in the USA found that more than 3000 students over an 18-year period received credit for classes that did not exist (Stein 2015). The National Collegiate Athletic Association (NCAA) in the USA has been investigating at least 20 universities for academic misconduct involving cheating by athletes (National Public Radio staff 2015).

A President of Hungary was recently forced to resign amid accusations of plagiarism of academic work, as was a German Minister of Defense (Marinas 2014; The Associated Press 2012). Fifteen Chinese nationals were recently indicted for hiring others to take university admission tests, including the Scholastic Aptitude Test (SAT) and the Graduate Record Exam (GRE), in their places (Strauss 2015). In the summer of 2015, the Prime Minister of Moldova resigned amid reports that his high school and university diplomas were fraudulent (Agence France-Presse 2015).

Academic integrity and academic dishonesty are a concern for several reasons. First, reviews of research on academic dishonesty have almost always found that more than half of students admit to cheating and plagiarism (Brown et al. 2010; Chertok et al. 2014). In fact, most reviews have found the prevalence of cheating and/or plagiarism to be above $70 \%$ (Chapman et al. 2004; Gallant et al. 2014; LaDuke 2013). Second, when students engage in academic dishonesty, their assessment results are faulty (Desalegn and Berhan 2014; Happel and Jennings 2008; Munoz-Garcia and Aviles-Herrera 2014). This inaccuracy in assessment results may be related to poorer student learning (Brimble and Stevenson-Clarke 2005) and may also damage the reputations of universities (Engler et al. 2008; Happel and Jennings 2008). Finally, academic dishonesty may be a predictor of dishonesty in the workplace (Desalegn and Berhan 2014).

Much of the published research on academic dishonesty has relied on administering surveys to samples of university students. These surveys typically gather some demographic data, 
along with self-reports about how often these students participate in various acts that might be considered academically dishonest. These surveys may also collect information about attitudes and academic dishonesty and reasons for engaging in academic dishonesty. The large majority of these studies has been conducted in the USA (e.g., Krueger 2014; Levy and Rakovski 2006; Morris 2012; Owunwanne et al. 2010; Sendag et al. 2012a, b). Similar studies have also been conducted in other countries where English is widely spoken (e.g., Bermingham et al. 2010; Brimble and Stevenson-Clarke 2005; de Lambert et al. 2006; Jurdi et al. 2011) as well as in other Western European countries (e.g., Colnerud and Rosander 2009; Farnese et al. 2011; Karassavidou and Glaveli 2006) and Asian countries (Ali et al. 2012; Koul et al. 2009; Lin and Wen 2007; Park et al. 2013). However, much less work has been done in other parts of the world, including Africa, South America, and Eastern Europe.

In Romania, some research has looked at specific features of academic dishonesty. For example, Andrei and his colleagues (2009) looked specifically at predictors of whether university students in Romania would copy from other students' exams. Teodorescu and Andrei (2009) examined students' beliefs about cheating by faculty and fellow students. Badea-Voiculescu (2013) found a high level of acceptance of plagiarism among medical students in Romania.

Anderman and Danner (2008) and Murdock and Anderman (2006) proposed a motivation framework for academic dishonesty. The framework is based on theoretical models of academic motivation that make a distinction between students who see academic work as an opportunity to learn and understand and students who see academic work as a means to external goals. The Murdock and Anderman framework of academic dishonesty addresses on three questions.

The first question is What is my purpose? This question is derived primarily from achievement goal theory (Urdan 1997). Students who are motivated by extrinsic goals may see academic dishonesty as a viable option for reaching those goals. However, students who are more concerned about the intrinsic interest of their academic work might find these goals disrupted by academic dishonesty.

The second question in the motivation framework is Can I do this? Expectancy-value theory (Wigfield and Eccles 2000) and self-efficacy theory (Bandura 1997) provide the foundation for this question. These theories suggest that students would be more motivated to engage in academic dishonesty if they are less confident in their ability to be successful otherwise. In addition, outcome expectation may influence motivation. For example, even if a student feels confident in being able to be successful academically, the student may also feel that assessments are unfair, which reduces the value of the effort to be successful and increases the value of academic dishonesty, yielding an interaction between self-efficacy and outcome expectations.

The third question in the motivation framework is What are the costs? This question is primarily based on expectancy-value theory. Costs might include the costs of being caught engaging in academic dishonesty, but they may also include costs to the student's own selfimage. Thus, the likelihood of getting caught and the severity of the expected consequences for being caught would influence a student's motivation. At the same time, a student's personal sense of morality would also influence the student's likelihood of engaging in academic dishonesty.

In addition to decades of research supporting achievement goal theory, expectancy-value theory, and self-efficacy theory, more recent research has supported elements of the Murdock and Anderman framework specifically in the context of post-secondary academic. These 
include studies confirming that internal learning goals are related to lower cheating rates than external performance goals (e.g., Kauffman and Young 2015; Miller et al. 2011; Yang et al. 2013). Studies have also confirmed that lower academic self-efficacy predicts academic dishonesty (e.g., Ogilvie and Stewart 2010; Patall and Leach 2015; Yang et al. 2013). Finally, studies have also confirmed that a balance of costs versus benefits predicts academic dishonesty (e.g., Ogilvie and Stewart 2010; Yang et al. 2013).

To the extent that there is a culture that is tolerant of academic dishonesty in Romanian universities, or any other academic institutions, this culture would be reflected in the motivation of both students and scholars to engage in academic dishonesty. Bailey (2012) has argued that since 1989, it has become fashionable in Romania for government officials to have graduate degrees. University officials have also recently been accused of, and even arrested for, accepting bribes in exchange for admissions and examination influence (Newsromania 2013; Romania Insider 2014). In these cases, the answer to the question What Is My Purpose? involves external rewards rather than intrinsic value. Given that academic dishonesty seems to be widespread in Romania and widely accepted by students, the answer to the question Can I Do This? is affirmative. Among public figures, the consequences of academic dishonesty have been negligible until recent years. Even with the clear evidence of Ponta's plagiarism, it took years and multiple reversals before there was enough pressure for him to rescind his degree. This inconsistent progress continues. For example, the Coalition for Clean Universities has begun to rate Romanian universities more highly in the last few years (Cole 2013; MungiuPippidi 2011). However, the Romanian National Research Council resigned in 2013 in protest because a range of reform efforts to review work based on merit, reduce cronyism, and increase transparency were reversed (Abbott 2013). In this climate of change in Romanian academia, the answer to the question What Are The Costs? may be that the costs are increasing, but this is not clear.

Given global concerns about academic dishonesty (AD) at universities, the visibility of these concerns in Romania as reported in the media, and the lack of more rigorous research on $\mathrm{AD}$ in Romania, the purpose of this study is to investigate the patterns and predictors of $\mathrm{AD}$ among university students in the country. More specifically, we addressed three research questions:

- What is the factorial structure of AD behaviors?

- What predictors of AD behaviors have the largest effects?

- To what extent do previous consequences of $\mathrm{AD}$ behaviors predict the perceived acceptability of AD behaviors?

\section{Methods}

\section{Survey development}

Guided by the recommendations of DeVellis (2012), we developed the survey to gather general demographic information about the participants and also to gather information about the experiences and beliefs of the participants regarding academic dishonesty. We reviewed empirical research on $\mathrm{AD}$ that involved administering surveys to students or faculty to ask them about academic dishonesty. We identified 37 such peer-reviewed articles published since 
2000 in which the survey was included or descriptions of the academic behaviors were included. These 37 sources are each marked with an asterisk (*) in the "References" section of this article.

Based on these 37 sources, we composed items in the first section of our survey that asked about demographic characteristics typically investigated in this research. These demographic characteristics of participants include age, gender, name of school, education rank (undergraduate class, Masters, or doctoral student), field of study, grade point average, and whether the participant was receiving financial aid.

The second section of our survey lists 22 academic behaviors and asks participants to answer four questions about each behavior. Our goals in composing items were to develop a survey that could be widely applied across disciplines and academic contexts and to include a comprehensive range of $\mathrm{AD}$ behaviors based on the literature.

Items in this second section of our survey were composed to meet several criteria: first, items needed to describe possible AD behaviors, and second, the AD behaviors that should not be specific to particular contexts. For example, we did not include items specific to laboratory work, or online versus face-to-face classes. Third, very specific behaviors from the literature were subsumed within more general items in our instrument. For example, a behavior description from a previous study, such as submitted work from a more senior student as your own, was subsumed within our item asking about copying all or part of someone else's work in your own assignment without acknowledging the author. For each of the $22 \mathrm{AD}$ behaviors included in the survey, participants were asked how acceptable that behavior is to them, how often they have seen others engage in that behavior since they have been in their current programs, how often they have engaged in that behavior themselves since they have been in their current programs, and what consequences they faced if they had ever been caught engaging in each behavior.

\section{Data collection}

Romanian faculty members were recruited through (1) invitations sent to distribution lists and newsletters of relevant organizations such as the Society for Romanian Studies and the Romanian Studies Association of America, (2) announcements at relevant conferences, and (3) professional connections based on prior work in Romania. These faculty members were instructed to recruit university students at their home institutions from a range of specialties and a range of academic levels. Data were collected over an 8-month period. Participants had the option of completing paper surveys or identical electronic surveys posted to SurveyMonkey. All data collection was anonymous.

\section{Results}

\section{Institutional descriptors}

Data were collected from students at six public universities in Romania: Universitatea BabesBolyai, Universitatea din Bucuresti, Universitatea Tehnica din Cluj Napoca, Universitatea din Pitesti, Universitatea Transilvania, and Academia de Studii Economice, Bucuresti. Most Romanian universities do not rank high enough to be included in the major worldwide university rankings (e.g., Academic Ranking of World Universities, Times Higher Education 
University Rankings, Quacquarelli Symonds World University Rankings) (Ives and Badescu 2015). However, in 2007, Ad Astra published an overall ranking of 49 universities within Romania based on the number of scholarly publications in Institute for Scientific Information (ISI) journals per 100 faculty members. Universities with no recorded publications in ISI journals were not listed. All six universities involved in this study were included in the list and were ranked 2nd, 3rd, 9th, 25th, 30th, and 42nd out of 49. The Webometrics Ranking of World Universities (WRWU) (Webometrics Ranking of World Universities 2015) includes the largest number of universities worldwide of any university ranking source and ranks universities based on sources available on the Internet, including Google Scholar and Scimago. The rankings are based on a weighted combination of visibility, presence, openness, and balance. According to the July 2014 results, the six participating universities were ranked 1st, 3rd, 5th, 8th, 11th, and 20th out of 108 Romanian universities, while the highest world rank for these universities was 785th. Both rankings indicate that the six participating sites for this study are among the highest ranked universities in Romania.

\section{Participant descriptors}

A total of 1127 Romanian university students participated in the study. Ages ranged from 18 to 57 years old $(M=21.43, \mathrm{SD}=4.43)$. The sample included 813 females and 312 males.

As a signatory to the Bologna Process, Romania is a member of the European Higher Education Area (European Higher Education Area 2015). This means, in part, that undergraduate university degrees in Romania are 3-year degrees. Participants were asked to indicate the current level of their coursework. Our sample included 479 first-year undergraduates, 235 second-year undergraduates, 331 third-year students, 76 Masters students, and 5 doctoral students.

Participants were asked to list their major or specialty area. These areas were coded according to the International Standard of Classification developed by the UNESCO Institute of Statistics (2015). The number of participants whose specialties were included in each category are shown in Table 1.

Table 1 UNESCO classification of majors/specialties

\begin{tabular}{ll}
\hline Category & $\begin{array}{c}\text { Number of } \\
\text { participants }\end{array}$ \\
\hline Generic Programmes & 0 \\
Education & 0 \\
Arts and Humanities & 2 \\
Social Sciences, Journ. and Info. & 640 \\
Business, Administration and Law & 227 \\
Natural Sciences, Math. and Stat. & 0 \\
Information and Commun. Tech. & 180 \\
Engineer., Manufac. and Construc. & 58 \\
Agriculture, Forest., Fish. and Vet. & 0 \\
Health and Welfare & 0 \\
Services & 8 \\
\hline
\end{tabular}


In Romania, grades are typically reported on a ten-point scale. In some cases, students reported grades on different scales. We converted all of these grades to percents out of the maximum possible. The mean grade percent was 79.96 with a standard deviation of 11.96. A total of 260 participants reported that they were receiving government scholarship support, while 886 were not.

\section{What is the factorial structure of AD behaviors?}

To explore patterns of $\mathrm{AD}$ behavior, we ran a principal component factor analysis with varimax rotation on participants' reports of how often they engaged in each of the $22 \mathrm{AD}$ behaviors listed in the instrument. According to the scree plot, the first factor was by far the strongest, with the remaining factors tailing off gradually. Eigenvalues for six of the factors were above 1. The five-factor solution yielded an interpretable solution (DeVellis 2012). This five-factor solution accounted for $56.66 \%$ of the total variance. The Kaiser-Meyer-Olkin measure of sampling adequacy was .877 . Bartlett's test of sphericity yielded a $p$ value <.0005.

Table 2 reports the rotated component matrix for this solution. The first factor included five items, with Cronbach's alpha $=.883$. Elimination of individual items did not increase internal consistency, and all five items involved using inappropriate information on tests. This first factor accounted for $30.85 \%$ of the total variance. The second factor initially included six items, with Cronbach's alpha $=.819$. Elimination of one item raised the internal consistency to

Table 2 Rotated factor loadings for exploratory factor analysis of AD behaviors

\begin{tabular}{|c|c|c|c|c|c|}
\hline Content & Test info & Assignments & False info & Sabotage & Test taker \\
\hline Take a test for someone else & .043 & .023 & .050 & .021 & .845 \\
\hline Another person takes your test & .035 & .111 & .043 & .092 & .813 \\
\hline Get info from others during a test & .780 & .144 & .189 & .016 & .057 \\
\hline Give info to others during a test & .769 & .183 & .195 & -.037 & -.010 \\
\hline Unauthorized materials on a test & .644 & .229 & .123 & .191 & .102 \\
\hline Give test info to others in advance & .633 & .373 & .042 & .174 & .052 \\
\hline Get test info from others in advance & .638 & .348 & .051 & .212 & .046 \\
\hline Submit assignment more than once & .254 & .441 & .079 & .145 & .166 \\
\hline Allow others to copy assignment & .272 & .729 & .164 & -.041 & .013 \\
\hline Copy another's assignment & .277 & .734 & .183 & .069 & .013 \\
\hline Complete another's assignment & .128 & .745 & .142 & .097 & .003 \\
\hline Other completes your assignment & .095 & .757 & .161 & .161 & .061 \\
\hline Collaborate on individual task & .292 & .532 & .320 & -.091 & -.026 \\
\hline Copy others' work without citing & .126 & .186 & .740 & -.007 & .013 \\
\hline Paraphrase without citing & .153 & .100 & .776 & .001 & .034 \\
\hline List references not actually read & .257 & .245 & .676 & .081 & -.009 \\
\hline Fabricate false references & .072 & .150 & .572 & .298 & .160 \\
\hline Fabricate false info or results & .165 & .141 & .492 & .413 & -.008 \\
\hline False excuse to delay & .278 & .241 & .381 & .370 & .041 \\
\hline Damage others' work & .034 & .090 & .094 & .729 & .049 \\
\hline Block others' access to resources & .110 & .020 & .052 & .763 & .056 \\
\hline Not report others' cheating & .547 & .075 & .300 & .009 & -.061 \\
\hline
\end{tabular}


alpha $=.821$. The remaining five items all were related to cheating on assignments. The eliminated item involved using the same assignment for more than one course without permission. This second factor accounted for additional $7.55 \%$ of the total variance. The third factor initially included seven items with alpha $=.767$. Elimination of one item raised the internal consistency to .778 , and the six remaining items were all related to students using false information, including plagiarism. The eliminated item involved failing to report the academic dishonesty of another student. This third factor accounted for additional $6.82 \%$ of the total variance. The fourth factor involved only two items, with internal consistency of .515. Both items involved sabotaging the work of other students. This fourth factor accounted for additional $6.07 \%$ of the total variance. The fifth factor also involved two items, with internal consistency of .589. Both items involved situations where the wrong student took an exam. This fifth factor accounted for additional $5.37 \%$ of the total variance.

To explore the factor structure further, we reran the factor analysis, forcing the number of factors to be equal to 4 . In this case, the first three factors remained intact, and the last two combined into a single factor with internal consistency of only .169, suggesting that the last two factors are relatively independent of each other.

In addition, because the last two factors in the five-factor solution had relatively weak internal consistency, we also generated a three-factor solution to see if the items in these two factors might load onto any of the first three factors that had stronger internal consistency. This three-factor solution yielded one factor including 18 items with an internal consistency of only .537 as well as two factors of two items each with internal consistencies of .589 and .515 , respectively. For the first factor, removal of items only improved internal consistency to .538 . Further, this one large factor did not lend itself to a clear interpretation.

Factor analysis involves finding an optimal balance of statistical strength as well as factors that can be interpreted in meaningful ways (DeVellis 2012). Given that the fivefactor structure yielded stronger internal consistency for at least three factors, as well as clearer interpretations for all five factors, compared to the other solutions, we prefer the five-factor solution. The three more robust factors were described as using inappropriate information on tests, cheating on assignments, and submitting false information (including plagiarism).

\section{A note on tests of statistical significance}

Two limitations of traditional significance testing apply to this study. First, as the number of participants increases, smaller effects are more likely to reach conventional statistical significance $(\alpha=.05)$. Second, as more statistical tests are carried out within the same study, concerns about overall type I error inflation rise. For both of these reasons, although we report $p$ values for statistically significant results, we focus our interpretations and discussions on the effect size results (Ives 2003).

\section{Which predictors of AD behaviors have the largest effects?}

We conducted one-way ANOVAs on categorical predictors of $\mathrm{AD}$ behavior, where $\mathrm{AD}$ behavior was estimated by the mean score of the items reporting participants' engagement in those $\mathrm{AD}$ behaviors. When the assumption of equal variance was violated according to Levene's test, we report the adjusted Brown-Forsythe probabilities. The results for these ANOVAs can be found in Table 3 . 
Table 3 ANOVA results for categorical predictors of overall $\mathrm{AD}$ behavior

\begin{tabular}{llc}
\hline Predictor & $F$ statistic & $p$ value \\
\hline Gender & .045 & .738 \\
University & .602 & .187 \\
Specialty & .604 & .697 \\
Scholarship & .106 & .568 \\
\hline
\end{tabular}

For predictors that were scalar rather than categorical, we conducted Pearson correlation coefficient tests. Results for these correlations are reported in Table 4, including proportions of variance for statistically significant results.

These two tables show that only two of our nine predictors have statistically significant relationships with overall $\mathrm{AD}$ behavior-how often participants observed other students engage in the behaviors and how acceptable participants believed the behaviors were. Note that Cohen's (1988) guidance suggests that a correlation should be at least .10 to be considered small, and only one of these two statistically significant predictors exceeds this minimum.

Our factor analysis of the $22 \mathrm{AD}$ behaviors identified five factors plus two additional individual items. We tested the possibility that some predictors predict individual factors, even though they did not predict overall AD behavior. To do this, we ran the same ANOVAs and correlations for each of the nine predictors against each of the five factors listed in Table 2 as well as the two individual items. Because this is a large number of statistical tests, an alpha level of .05 for each test would inflate the overall type I error rate for the 63 tests to about .941 . Instead, we set the individual alpha level for each of these 63 tests at .001 . This more conservative alpha level yielded an overall alpha level of about .06. Further, we focused on interpretation of effect sizes for these results over statistical significance.

Of the nine predictors, six still yielded no significant relationship with any of the five factors or the two individual items. These six predictors were gender, university, specialty, scholarship, grade average, and age. Further, they each accounted for less than $1 \%$ of the variance in any of the factors or the two individual items.

Level of coursework was significantly correlated with two factors and both of the individual items, as shown in Table 5. None of these results accounted for more than $1.5 \%$ of the variance in the factor or item results, and these effect sizes are all in the small range based on Cohen's guidance.

By contrast, observing others and the acceptability of AD behaviors were reliable predictors with stronger effect sizes for almost all of the factors and individual items. Table 6 shows the correlations, proportion of variance, and probabilities for these tests. Of the 14 tests reported in this table, three are considered large based on Cohen's guidance $\left(r>.5, r^{2}>.25\right)$, five are

Table 4 Correlation results for scalar predictors of overall AD behavior

\begin{tabular}{llr}
\hline Predictor & $r$ statistic $\left(\right.$ if $\left.p<.05, r^{2}\right)$ & $p$ value \\
\hline Level of coursework & -.010 & .750 \\
Grade average & -.057 & .093 \\
Age & -.030 & .327 \\
Observe others & $.114(.013)$ & $<.0005$ \\
Acceptability & $.087(.008)$ & .004 \\
\hline
\end{tabular}


Table 5 Significant correlations between level of coursework and factors or individual items

\begin{tabular}{llr}
\hline Factor or item & $r\left(r^{2}\right)$ & $p$ \\
\hline False info & $.104(.011)$ & .001 \\
Test info & $.122(.015)$ & $<.0005$ \\
Reusing & $.118(.014)$ & $<.0005$ \\
Reporting & $.114(.013)$ & $<.0005$ \\
\hline
\end{tabular}

considered medium $\left(r>.3, r^{2}>.09\right)$, and four are considered small $\left(r>.1, r^{2}>.01\right)$. All of these are significant at $p<.0005$. In every case where the relationship was significant, a stronger predictor of those AD behaviors was observed than acceptability.

\section{To what extent do previous consequences of $A D$ behaviors predict the perceived acceptability of AD behaviors?}

We sorted participants into three categories based on whether they reported engaging in any of the $\mathrm{AD}$ behaviors and whether they reported experiencing any consequences for being caught engaging in those behaviors. Of the 1127 participants, 613 reported engaging in AD behaviors and faced consequences for those behaviors, 435 had engaged in $\mathrm{AD}$ behaviors and never faced any consequences, and 53 had not engaged in any AD behaviors. Thus, about $95 \%$ of participants acknowledged engaging in $\mathrm{AD}$ behaviors during their current degree programs. We ran a one-way ANOVA to test the hypothesis that students who faced consequences of AD behaviors would see those behaviors as less acceptable than those students who had not faced any consequences. Homogeneity of variance was acceptable according to Levene's test $(p=.298)$. The omnibus ANOVA comparing all three groups was significant $(F=22.034$, $p<.0005)$. Post hoc Tukey's tests were not consistent with our hypothesis. Students who engaged in $\mathrm{AD}$ behaviors and faced consequences were no less likely to see those behaviors as acceptable than students who engaged in $\mathrm{AD}$ behaviors and faced no consequences $(p=.630$, $d=.06$ ). By contrast, the group that did not engage in any AD behaviors was significantly less likely to see those behaviors as acceptable than either of the other two groups $(p<.0005$ and $d>.8$ in both cases). In other words, students who never engaged in AD behaviors were

Table 6 Correlations between observing others or acceptability of AD behaviors and AD behavior factors and individual items

\begin{tabular}{llllr}
\hline & \multicolumn{2}{l}{ Observe } & & \multicolumn{2}{l}{ Acceptability } \\
\cline { 2 - 3 } & \multicolumn{1}{r}{$r\left(r^{2}\right)$} & $p$ & $r\left(r^{2}\right)$ & $p$ \\
\hline False info & $.589(.347)$ & $<.0005$ & $.380(.144)$ & $<.0005$ \\
Test info & $.623(.388)$ & $<.0005$ & $.438(.192)$ & $<.0005$ \\
Assignments & $.560(.314)$ & $<.0005$ & $.406(.165)$ & $<.0005$ \\
Test taker & $.119(.014)$ & $<.0005$ & $.118(.014)$ & $<.0005$ \\
Sabotage & $.175(.031)$ & $<.0005$ & $.148(.022)$ & $<.0005$ \\
Reusing & $.364(.132)$ & $<.0005$ & $.270(.073)$ & $<.0005$ \\
Reporting & $.472(.223)$ & $<.0005$ & $.249(.062)$ & $<.0005$ \\
\hline
\end{tabular}


strongly more likely to see those behaviors as unacceptable than those that had engaged in those behaviors, whether they faced consequences for those behaviors or not.

\section{Discussion}

About $95 \%$ of our sample reported having engaged in one or more acts of AD. This is a somewhat higher rate than that reported in other studies, although reviews often find rates higher than 70\% (Chapman et al. 2004; Gallant et al. 2014; LaDuke 2013). However, we urge caution in making inferences based on these comparisons. Rarely is the same instrument used in more than one published study. This means that these comparisons are being made across studies that do not always include the same behaviors. Some studies focus on particular educational settings or particular disciplines. In other words, differences in AD prevalence may be the result of a variety of differences between the studies. In addition, the instrument used in this study was derived from a review of literature with the goal of including a comprehensive range of $\mathrm{AD}$ behaviors. Instruments with a wider range of $\mathrm{AD}$ behaviors should be expected to yield higher overall rates. However, this does not imply that the AD rates would be higher for each individual behavior. Comparisons of the self-reported frequencies of all of our 22 behaviors with frequencies from similar behaviors across the literature are beyond the scope of this article. However, a few examples will illustrate that the participants in this study may not have particularly high rates of AD behaviors compared to students in other studies. The percent of students reporting copying from others on a test ranged from 7.5 to $84.8 \%$. About $68.2 \%$ of the students in our study acknowledged copying from others on the test. Students in other studies confirmed submitting someone else's work as their own in 5 to $55.3 \%$ of the time. Our participants reported this behavior to be $30.6 \%$ of the time. In other studies, 7.2 to $85.9 \%$ of students reported working with other students on an individual assignment. Of our participants, $70.3 \%$ reported this behavior. Finally, participants in other studies reported submitting a previous assignment to another course without instructor permission in 5.8 to $9.7 \%$ of the time. About $33.9 \%$ of our participants reported resubmitting an assignment to another course without permission. The broader point to be made is that inconsistent results across studies and differences in instruments, context, academic specialties, and other factors make generalizations about these results unreliable. Nevertheless, an overall rate of $95 \%$ of students engaging in academically dishonest behaviors suggest that students have ample motivation to engage in these behaviors in Romania. The Murdock and Anderman motivation framework for academic dishonesty may explain this high rate. Higher education is seen as a mark of prestige in Romania. If this is the answer to the question What is my purpose? in the motivational framework, research has previously found that students with external goals for education are more likely to engage in academic dishonesty than students who have internal goals for higher education. Further, public figures have faced minimal consequences for findings of plagiarism, although this pattern may be changing in Romania. To the extent that students see public figures not facing consequences for their acts of academic dishonesty, they may be more likely to answer the question What are the costs? based on that cultural context. If the costs are seen as minimal, according to the motivational framework, then academic dishonesty is more likely to occur.

Factor analysis of student reports about how often they engaged in 22 different AD behaviors resulted in a five-factor solution that explained about $56.66 \%$ of the total variance in these data. The five factors were related to coherent constructs - false information including 
plagiarism, inappropriate test information, cheating on assignments, tests taken by someone other than the person named on the test, and sabotaging the work of other students. The first three of these factors yielded strong internal consistencies.

Other researchers have also looked for a factorial structure to AD behaviors. Five factors were identified in a study of AD involving the use of the Internet (Akbulut et al. 2008). These factors included plagiarism, falsification, unauthorized help, fraudulence, and delinquency. Plagiarism and falsification seem to be combined in our results. The unauthorized help factor seems to be subsumed under our factor for cheating on assignments. The fraudulence factor seems to be a mixture, including sabotaging the work of others, fabricating information, selling a project online, and more. The delinquency factor also seems to be less than coherent, including using the same assignment for more than one course, spelling mistakes, citing an Internet source too much, and doing a friend's assignment. Colnerud and Rosander (2009) identified five factors in their data but concluded that internal consistency was not strong enough in three of them for further analysis. As a result, they focused their analyses and discussion on submitting someone else's text as the student's own and fabricating references and results. These align with our factor of false information, including plagiarism. We conclude that our results confirm the results from other studies supporting factors for plagiarism and some cheating on assignments. More research is needed on the factor structure of AD behaviors to determine whether there is a reliable factor structure across a range of behaviors and whether this structure is consistent across populations and settings.

We found that how often students observed other students engage in AD behaviors and how acceptable students believed these behaviors to be were weak but statistically significant predictors of overall AD behavior. These two predictors were also significantly related to all of the separate factors, as well as the two individual items that did not fit well into any of the five factors. In several cases, these effects were also larger than for overall AD behavior. For example, we found large effect sizes when observing others was used to predict false information, inappropriate test information, and cheating on assignments. The acceptability of AD behaviors significantly predicted these same three factors with medium effect sizes. These results provide some additional support for the validity of these factors from our factor analysis. Prior research has also shown that the perceived acceptability of AD behaviors predicts those behaviors (Bisping et al. 2008; Jensen et al. 2002; Nonis and Swift 2001) and that observing others engage in $\mathrm{AD}$ behaviors is associated with higher levels of $\mathrm{AD}$ behaviors (Rettinger and Kramer 2009; Teodorescu and Andrei 2009). To the extent that students observe others engaging in academic dishonesty, they may be more likely to conclude that these behaviors are doable, answering the question Can I do this? from the motivational framework.

However, we also found that the effect sizes for the rest of our predictors of AD behaviors, whether overall or for specific factors and items, were negligible or very small and those relationships were not significant. This is particularly unexpected, given that our sample size is larger than the sample sizes of most previous studies. Results from previous studies have often been inconsistent. For example, some studies have found gender differences in AD behaviors (Krueger 2014; Unal 2011), while others have not (Kucuktepe 2011; Moberg et al. 2008). Similarly, findings in previous studies are not consistent for how well class level predicts AD behavior (Kucuktepe 2011; Watson and Sottile 2010). Major or specialty may more consistently predict AD behavior (Jurdi et al. 2011; Moberg et al. 2008; Rakovski and Levy 2007), but these results may depend on which specialties are included in the studies. Given the inconsistency of results for demographic predictors of AD behaviors, a broader review of this 
research, including meta-analyses, may offer some helpful insight into the relationships between these predictors and AD behavior.

We also found that students who faced consequences for their $\mathrm{AD}$ behaviors did not see $\mathrm{AD}$ behaviors as more unacceptable than students who faced no consequences for their $\mathrm{AD}$ behaviors. However, students who never engaged in $\mathrm{AD}$ behaviors were more likely to see those behaviors less unacceptable than students who did engage in those behaviors. Olafson et al. (2013) found that students who did not cheat had more sophisticated moral reasoning skills than those who did cheat, regardless of whether those who did cheat were caught or not. Our results suggest that punishment may not be an effective approach to changing students' beliefs about AD behaviors, and the findings of Olafson and her colleagues may suggest a reason why. This issue warrants further investigation. These results also may be in conflict with the motivational framework. We would expect that students who faced consequences for their academic dishonesty would see the costs as relatively high compared to students who did not face consequences. If that were the case, then we would expect students who faced consequences to see $\mathrm{AD}$ as less acceptable than students who did not face consequences. However, we found that the rates of academic dishonesty were not different for these two groups.

One important limitation of this study is that the sample is not representative of university students in Romania in some ways. While we have included students from six public universities, we have not included students from private universities. Our sample includes good representation across undergraduate years, but representation at the doctoral level is particularly poor. We have good representation across three of the UNESCO classifications of specialties and some representation in a fourth specialty. However, our sample includes little or no representation in seven other fields.

While concerns about academic integrity have been raised worldwide, research to date has not adequately supported a consensus about the factors of AD behaviors. Further, demographic predictors of AD behaviors have not consistently predicted those behaviors. These results have implications for decisions about efforts to reduce $\mathrm{AD}$ behaviors and should also guide further research.

\section{References}

Abbott, Alison. (2012). Romanian scientists fight plagiarism. Retrieved August, 18, 2015, 2015, from http:/www.nature.com/news/romanian-scientists-fight-plagiarism-1.11170.

Abbott, Alison. (2013). Romanian science in free fall. Retrieved August, 18, 2015, 2015, from http://0-www. nature.com.innopac.library.unr.edu/news/romanian-science-in-freefall-1.13579

Abbott, Alison. (2015). Scientists protest Romanian decree on PhD revocation. Retrieved August 18, 2015, 2015 , from http://0-www.nature.com.innopac.library.unr.edu/news/scientists-protest-romanian-decree-on-phdrevocation-1.16666.

Agence France-Presse. (2015). Moldova's prime minister resigns over 'fake diploma' scandal. Retrieved August 18, 2015, 2015, from http://news.yahoo.com/moldovas-prime-minister-quits-over-fake-diploma-scandal103948115.html;_ylt=A0LEVwkATXtV21wAj_pXNyoA; ylu=X3oDMTEyYmZ1ZmJzBGNvbG8 DYmYxBHBvcwMxBHZ0aWQDQjAzOTZfMQRzZWMDc2M-.

*Akbulut, Yavuz, Sendag, Serkan, Birinci, Gurkay, Kilicer, Kerem, Sahin, Mehmet C., \& Odabasi, Hatice F. (2008). Exploring the types and reasons of Internet-triggered academic dishonesty among Turkish undergraduate students: development of Internet-Triggered Academic Dishonesty Scale (ITADS). Computers \& Education, 51, 463-473.

*Ali, Wan Zah Wan, Ismail, Habsah, \& Cheat, Tan Tien. (2012). Plagiarism: to what extent it is understood? Procedia Social and Behavioral Sciences, 59, 604-611.

Anderman, E. M., \& Danner, F. (2008). Achievemenet goals and academic cheating. Revue Internationale de Psychologie Sociale, 21(1), 150-180. 
Andrei, T., Teodorescu, D., Stancu, S., \& Oancea, B. (2009). Some features of the non-academic behavior in the Romanian universities. Procedia Social and Behavioral Sciences, 1, 1964-1968. doi:10.1016/j. sbspro.2009.01.345.

Baciu, L. L., Bunda, N. R., Andreea, I., \& Asandului, M. (2010). Motivation and performance in higher education systems. The case of Romanian universities. Metalurgia International, 15(2), 67-72.

Badea-Voiculescu, O. (2013). Attitude of Romanian medical students towards plagiarism. Romanian J Morphol Embryol, 5(3 Supplement), 907-908.

Bailey, Jonathan. (2012). The plagiarism insanity in Romania. Retrieved August 18, 2015, 2015, from http://www.plagiarismtoday.com/2012/07/02/the-plagiarism-insanity-in-romania/.

Bandura, A. (1997). Self-efficacy: The exercise of control. Neew York: Freeman.

*Bermingham, Vera, Watson, Susan, \& Jones, Martin. (2010). Plagiarism in UK schools: is there a postcode lottery? Assessment \& Evaluation in Higher Education, 35(1), 1-15.

*Bisping, Timothy O., Patron, Hilde, \& Roskelley, Kenneth. (2008). Modeling academic dishonesty: the role of student perceptions and misconduct type. Journal of Economic Education, 39(1), 4-21.

*Brimble, M., \& Stevenson-Clarke, P. (2005). Perceptions of the prevalence and seriousness of academic dishonesty in Australian universities. Aust Educ Res, 32(3), 19-44.

Brown, B. S., Weible, R., \& Olmosk, K. E. (2010). Business school deans in student academic dishonesty: a survey. Coll Stud J, 44(2), 299-308.

*Chapman, Keneth J., Davis, Richard, Toy, Daniel, \& Wright, Lauren. (2004). Academic integrity in the business school environment: I'll get by with a little help from my friends. Journal of Marketing Education, 26, 236-249.

Chertok, I. R., Azulay, B., Emily, R., \& Gilleland, D. (2014). Academic integrity in the online learning environment for health sciences students. Nursing Education Today, 34, 1324-1329.

Cohen, J. (1988). Statistical power analysis for the behavioral sciences (Second ed.). Hillsdale, NJ: Erlbaum.

Cole, Miles. (2013). Corruption in universities: a blueprint for reform. Retrieved August 18, 2015, 2015, from http://www.timeshighereducation.com/comment/opinion/corruption-in-universities-a-blueprint-forreform/2009139. article.

*Colnerud, Gunnel, \& Rosander, Michael. (2009). Academic dishonesty, ethical norms and learning. Assessment \& Evaluation in Higher Education, 34(5), 505-517.

Comsa, M., Tufis, C. D., \& Voicu, B. (2007). Romanian academic system: teachers' and students' opinions (pp. 128). Bucharest, Romania: Soros Foundation Romania.

de Lambert, K., Ellen, N., \& Taylor, L. (2006). Chalkface challenges: a study of academic dishonesty amongst students in New Zealand tertiary institutions. Assessment \& Evaluation in Higher Education, 31(5), 485503. doi: 10.1080/02602930600679415.

Desalegn, A. A., \& Berhan, A. (2014). Cheating on examinations and its predictors among undergraduate students at Hawassa University College of Medicine and Health Science, Hawassa, Ethiopia. BCM Medical Education, 14(89).

DeVellis, R. F. (2012). Scale development theory and applications (Third ed.). Los Angeles: Sage.

Engler, J. N., Landau, J. D., \& Epstein, M. (2008). Keeping up with the Joneses: students' perceptions of academically dishonest behavior. Teach Psychol, 35, 99-102. doi:10.1080/00986280801978418.

European Higher Education Area. (2015). Bologna Process-European Higher Education Area. Retrieved October 17, 2015, 2015, from http://www.ehea.info/.

Farnese, M. L., Tramontano, C., Fida, R., \& Paciello, M. (2011). Cheating behaviors in academic context: does academic moral engagement matter? Procedia Social and Behavioral Sciences, 29, 356-365. doi:10.1016/j. sbspro.2011.11.250.

Gallant, T. B., Van den Einde, L., Ouellette, S., \& Lee, S. (2014). A systematic analysis of cheating in an undergraduate engineering mechanics course. Sci Eng Ethics, 20, 277-298. doi:10.1007/s11948-013-9435-6.

Galloway, Andrew. (2013). The culture of plagiarized dissertations in Romania - a call for inquiry in the humanities - and beyond. Retrieved August 18, 2015, 2015, from http://integru.org/opinions/the-cultureof-plagiarized-dissertations-in-romania-a-call-for-inquiry-in-the-humanities-and-beyond.

Hantz, Peter. (2012). Romania - a country where plagiarism in medical sciences is tolerated. Retrieved August 18, 2015, 2015, from http://bolyai.eu/dok/plagium j.pdf

Happel, S. K., \& Jennings, M. M. (2008). An economic analysis of academic dishonesty and its deterrence in higher education. Journal of Legal Studies Educationq, 25(2), 183-214.

Ives, B. (2003). Effect size use in studies of learning disabilities. J Learn Disabil, 36, 490-504.

Ives, B., \& Badescu, G. (2015). Romanian scholarly productivity: recent history and recommendations. High Educ Res Dev, 34(5), 926-941.

*Jensen, Lene Arnett, Arnett, Jeffrey Jensen, Feldman, S. Shirley, \& Cauffman, Elizabeth. (2002). It's wrong, but everybody does it: academic dishonesty among high school and college students. Contemporary Educational Psychology, 27, 209-228. 
Jurdi, R., Hage, H. S., \& Chow, H. P. H. (2011). Academic dishonesty in the Canadian classroom: behaviours of a sample of university students. Can J High Educ, 41(3), 1-35.

Karassavidou, E., \& Glaveli, N. (2006). Towards the ethical or the unethical side? An explorative research of Greek business students' attitudes. Int J Educ Manag, 20(5), 348-364. doi:10.1108/09513540610676421.

Kauffman, Y., \& Young, M. (2015). Digital plagiarism: An experimental study of the effet of instructional goals and copy-and-paste affordance. Computers \& Education, 83, 44-56.

Koul, R., Clariana, R. B., Jitgarun, K., \& Songsriwittaya, A. (2009). The influence of achievement goal orientation on plagiarism. Learn Individ Differ, 19, 506-512.

*Krueger, Linda. (2014). Academic dishonesty among nursing students. Journal of Nursing Education, 53(2), 77-87.

Kucuktepe, S. E. (2011). Evaluation of tendency towards academic dishonesty levels of psychological counseling and guidance undergraduate students. Procedia Social and Behavioral Sciences, 15, 2722-2727. doi:10.1016/j.sbspro.2011.04.177.

LaDuke, R. D. (2013). Academic dishonesty today, unethical practices tomorrow? J Prof Nurs, 29(6), 402-406.

*Levy, Elliott S., \& Rakovski, Carter C. (2006). Academic dishonesty: a zero tolerance professor and student registration choices. Research in Higher Education, 47(6), 735-754.

*Lin, Chun-Hua Susan, \& Wen, Ling-Yu Melody. (2007). Academic dishonesty in higher education-a nationwide study in Taiwan. Higher Education, 54, 85-97.

Marinas, Radu-Sorin. (2014). Romanian PM gives up doctorate after years of plagiarism allegations. Retrieved August 18, 2015, 2015, from http:/www.reuters.com/article/2014/12/16/us-romania-ponta-idUSKBN0JU1N520141216.

Miller, A., Shoptaugh, C., \& Wooldridge, J. (2011). Reasons not to cheat, academicintegrity responsibility, and frequency of cheating. The Journal of Experimental Education, 79, 169-184. doi:10.1080 100220970903567830 .

*Moberg, Chris, Sojka, Jane Z., \& Gupta, Ashok. (2008). An update on academic dishonesty in the college classroom. Journal on Excellence in College Teaching, 19(1), 149-176.

Morris, R. C. (2012). The relative influence of values and identities on academic dishonesty: a quantitative analysis. Current Research in Social Psychology.

Mungiu-Pippidi, Alina. (2011). Civil society and control of corruption: assessing governance of Romanian public universities. International Journal of Educational Development, March 2011.

Munoz-Garcia, A., \& Aviles-Herrera, M. J. (2014). Effects of academic dishonesty on dimensions of spiritual well-being and satisfaction: a comparative study of secondary school and university students. Assessment \& Evaluation in Higher Education, 39(3), 349-363.

Murdock, T. B., \& Anderman, E. M. (2006). Motivational perspectives on student cheating: Toward an integrated model of academic dishonesty. Educational Psychologist, 41(3), 129-145.

National Public Radio staff. (2015). Academic foul: some colleges accused of helping athletes cheat. Retrieved August 18, 2015, 2015, from http:/www.npr.org/2015/06/13/414188857/academic-foul-some-collegesaccused-of-helping-athletes-cheat?utm_source=facebook.com\&utm_medium=social\&utm_campaign= npr\&utm_term=nprnews\&utm_content $=\overline{2} 0150614$.

Newsromania. (2013). The rector of Ovidius University in Constanta was arrested. Retrieved August 18, 2015, 2015, from http://www.newsromania.com/social/the-rector-of-ovidius-university-in-constanta-was-arrested

Nonis, S., \& Swift, C. O. (2001). An examination of the relationship between academic dishonesty and workplace dishonesty: a multicampus investigation. J Educ Bus, 77(2), 69-77.

Ogilvie, J., \& Stewart, A. (2010). The integration of Rational Choice and Self-Efficacy theories: A situational analysis of student misconduct. The Australian and New Zealand Journal of Criminology, 43(1), 130-155.

Olafson, L., Schraw, G., Nadelson, L., Nadelson, S., \& Kehrwald, N. (2013). Exploring the judgment-action gap: College students and academic dishonesty. Ethics \& Behavior, 23(2), 148-162. doi:10.1080 /10508422.2012.714247.

*Owunwanne, Daniel, Rustagi, Narendra, \& Dada, Remi. (2010). Students' perceptions of cheating and plagiarism in higher institutions. Journal of College Teaching and Learning, 7(11), 59-68.

*Park, Eun-Jun, Park, Seungmi, \& Jang, In-Sun. (2013). Academic cheating among nursing students. Nurse Education Today, 33, 346-352.

Patall, E. A., \& Leach, J. K. (2015). The role of choice provision in academic dishonesty. Contemporary Educational Psychology, 42, 97-110.

Popescu, I. (2014). Another Romanian politician suspected of plagiarism. Retrieved August, 18(2015), 2015.

*Rakovski, Carter C., \& Levy, Elliott S. (2007). Academic dishonesty: perceptions of business students. College Student Journal, 41(2), 466-481.

*Rettinger, David A., \& Kramer, Yair. (2009). Situational and personal causes of student cheating. Research in Higher Education, 50, 293-313.

Romania Insider. (2014). Pro-Dean at Bucharest's economic university, investigated for bribery. Retrieved August 18, 2015, 2015, from http://www.romania-insider.com/pro-dean-at-bucharests-economicuniversity-investigated-for-bribery/127892/. 
Schiermeier, Quirin. (2012a). Conflicting verdicts on Romanian prime minister's plagiarism. Retrieved August 18, 2015, 2015, from http://0-www.nature.com.innopac.library.unr.edu/news/conflicting-verdicts-onromanian-prime-minister-s-plagiarism-1.11047.

Schiermeier, Quirin. (2012b). Romanian panel calls prime minister a plagiarist. Retrieved August 18, 2015, 2015 , from http://0-www.nature.com.innopac.library.unr.edu/news/romanian-panel-calls-prime-minister-aplagiarist-1.10926.

Sendag, S., Duran, M., \& Fraser, M. R. (2012a). Surveying the extent of involvement in online academic dishonesty (e-dishonesty) related practices among university students and the rationale students provide: one university's experience. Comput Hum Behav, 28, 849-860. doi:10.1016/j.chb.2011.12.004.

*Sendag, Serkan, Duran, Mesut, \& Fraser, M. Robert. (2012b). Surveying the extent of involvement in online academic dishonesty (e-dishonesty) related practices among university students and the rationale students provide: one university's experience. Computers in Human Behavior, 28, 849-860. doi: 10.1016/ j.chb.2011.12.004

Stan, L., \& Turcescu, L. (2004). Politicians, intellectuals, and academic integrity in Romania. Problems of PostCommunism, 51(4), 12-24.

Stein, Letitia. (2015). University of North Carolina put on probation over academic fraud scandal. Retrieved August 18, 2015, 2015, from http://news.yahoo.com/university-north-carolina-sanctioned-amid-academicfraud-scandal-171941357-nfl.html.

Strauss, Valerie. (2015). SAT cheating scandal broadens with indictment of 15 Chinese nationals. Retrieved August 18, 2015, 2015, from http://www.washingtonpost.com/blogs/answer-sheet/wp/2015/06/03/satcheating-scandal-broadens-with-indictment-of-15-chinese-nationals/.

Stroe, Daniel. (2013). Romanian publisher gets prison sentence for plagiarism. Retrieved August 18, 2015, 2015 , from http://www.balkaneu.com/romanian-publisher-prison-sentence-plagiarism/.

Teodorescu, D., \& Andrei, T. (2009). Faculty and peer influences on academic integrity: college cheating in Romania. High Educ, 57, 267-282. doi:10.1007/s10734-008-9143-3.

The Associated Press. (2012). Romania: plagiarism scandal ensnares prime minister. Retrieved August 18, 2015, 2-15, from http://www.nytimes.com/2012/06/20/world/europe/romania-plagiarism-scandal-ensnares-primeminister.html? $\mathrm{r}=0$.

Unal, E. (2011). Examining the relationship between pre-service teachers' ethical reasoning level and their academic dishonesty levels: a structural equation modelling approach. Educational Research and Reviews, 6(19), 983-992. doi:10.5897/ERR11.259.

UNESCO Institute for Statistics. (2015). International standard of classification: fields of education and training 2013 (ISCED-F 2013)_-detailed field descriptions (pp. 96). Montreal, Canada: UNESCO Institute for Statistics.

Urdan, T. (1997). Achievement goal theory: Past results, future directions. In M. L. Maehr \& P. R. Pintrich (Eds.), Advances in Motivation and Achievement (Vol. 10, pp. 99-141). Greenwich, CT: JAI.

*Watson, George, \& Sottile, James. (2010). Cheating in the digital age: do students cheat more in online courses? Online Journal of Distance Learning Administration, XIII(I).

Webometrics Ranking of World Universities. (2015). Ranking web of universities: Romania. Retrieved October 12, 2015, 2015, from http:/webometrics.info/en/Europe/Romania.

Wigfield, A., \& Eccles, J. S. (2000). Expectancy-value theory of achievement motivation. Contemporary Educational Psychology, 25, 68-81.

Yang, S. C., Huang, C.-L., \& Chen, A.-S. (2013). An investigation of college students' perceptions of academic dishonesty, reasons for dishonesty, achievement goals, and willingness to report dishonest behavior. Ethics \& Behavior, 23(6), 501-522. doi:10.1080/10508422.2013.802651.

Zaharia, R. M. (2009). Performance of academic research in Romania: the view of academics from Bucharest University of Economics. Transformations in Business \& Economics, 8(3), 145-163. 